techniques permit earlier identification of these organisms, leading to early treatment with an antibiotic regimen which should contain metronidazole.

I thank Dr S Benatar, Professor P Folb, and Dr A Forder for their advice and help.

1 Sherwood, L G, and Bartlett, J G, New England fournal of Medicine, 1974, 290, 1237.

2 Masri, A F, and Grieco, M H, American fournal of Medicine, 1972, 263, 357.

${ }^{3}$ Nastro, L J, and Finegold, S M, American fournal of Medicine, 1973, 54, 482 .

${ }^{4}$ Chow, A W, Patten, V, and Guze, L B, fournal of Infectious Diseases, 1975, $131,182$.

${ }^{5}$ Tally, F P, Sutter, V L, and Finegold, S M, Antimicrobial Agents and Chemotherapy, 1975, 7, 672.

(Accepted 21 December 1977)

Department of Medicine, Groote Schuur Hospital, Cape Town, South Africa

JANET SEGGIE, MB, MRCP, registrar

\section{Listeria monocytogenes endocarditis in hypertrophic cardiomyopathy}

Infective endocarditis has been reported as a complication of hypertrophic cardiomyopathy, ${ }^{12}$ while Listeria monocytogenes is a rare causative organism in endocarditis. ${ }^{3}$ We report the first known case of $L$ monocytogenes endocarditis complicating hypertrophic cardiomyopathy.

\section{Case history}

A previously fit 53-year-old man was referred with a five-week history of fatigue, dizziness, exertional dyspnoea, and night sweats. He had lost weight, and two weeks previously had developed ankle oedema, for which digoxin and frusemide had been prescribed without noticeable improvement. He had been found to be anaemic and given oral iron supplements. He was pale and had slight ankle oedema. The carotid pulse was sharp and a systolic murmur was heard at both the cardiac apex and the left sternal edge. There were no specific signs of infective endocarditis and he was afebrile. A month later he was admitted to hospital for investigation of his persistent anaemia and his cardiac murmur. He had developed signs suggestive of endocarditis: fever, finger-clubbing, and splenomegaly. A new mitral pansystolic murmur and a new aortic immediate diastolic murmur were heard. Two days later splinter

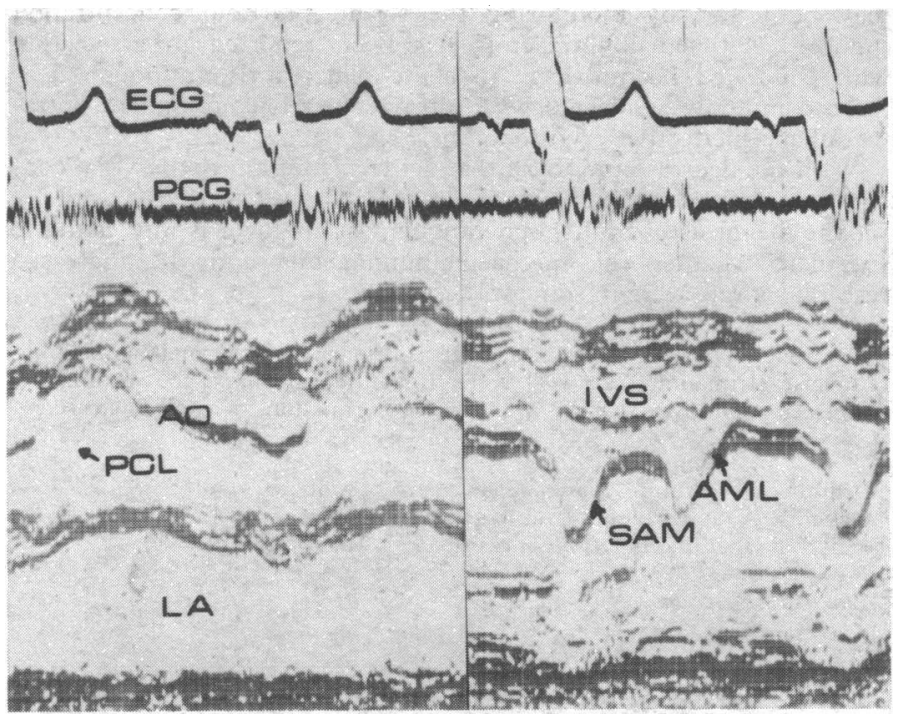

Electrocardiogram (ECG) and phonocardiogram (PCG) with echocardiogram showing aortic valve (AO), with premature partial closure (PCL), left atrium (LA), interventricular septum (IVS), and anterior mitral leaflet (AML) showing systolic anterior movement (SAM). haemorrhages appeared. Investigations showed a normocytic, normochromic anaemia (Hb $8.6 \mathrm{~g} / \mathrm{dl}$ ) and raised ESR ( $47 \mathrm{~mm}$ in $1 \mathrm{~h}$, Westergren). $L$ monocytogenes was isolated from seven bottles during serial blood cultures. An enlarged heart was seen on the chest radiograph and the electrocardiogram showed evidence of left ventricular hypertrophy.

The endocarditis was treated with penicillin in high dose, and over the subsequent weeks he progressively recovered. His fever settled and he began to gain weight; the aortic regurgitant murmur was no longer audible; and the anaemia resolved and the ESR fell to normal. One year after leaving hospital his only symptoms were occasional non-specific chest pains and infrequent episodes of dizziness, unrelated to each other or to exertion. The ejectionsystolic and mitral pansystolic murmurs persisted. An echocardiogram showed abnormalities typical of hypertrophic obstructive cardiomyopathy (see figure). ${ }^{4}$ There is systolic anterior movement of the anterior leaflet of the mitral valve. The left ventricular outflow tract is narrowed. The anterior leaflet of the mitral valve is thickened, and the septum is disproportionately thickened in comparison with the posterior left ventricular wall. There is premature partial closure of the aortic valve in mid-systole.

Treatment was subsequently begun with propranolol, $40 \mathrm{mg}$ thrice daily, since when he has had no further episodes of dizziness and only infrequent chest pain.

\section{Comment}

This report illustrates the need for an increased awareness of the risk of endocarditis in hypertrophic cardiomyopathy, since mortality and morbidity will be minimised by earlier diagnosis. The need for adequate antibiotic prophylaxis in this condition is also emphasised.

Furthermore, the case illustrates the usefulness of echocardiography in the diagnosis of this condition, particularly in the presence of endocarditis, when invasive methods would be better avoided. Echocardiography has also been used to show the anatomical site of vegetations in endocarditis. ${ }^{5}$ The investigation was not performed during our patient's illness, but its use in future cases may provide information about the sites of endocardial infection in hypertrophic cardiomyopathy, previously obtainable only at necropsy. ${ }^{12}$

We thank Dr C L Joiner for permission to report this case.

1 Vecht, R J, and Oakley, C M, British Medical fournal, 1968, 2, 455.

2 Wang, K, et al, American Heart fournal, 1975, 89, 359.

${ }^{3}$ Bassan, R, American fournal of Clinical Pathology, 1975, 63, 522.

${ }^{4}$ Mills, P G, Fournal of the Royal College of Physicians of London, 1977, 11, 335.

${ }^{5}$ Roy, P, et al, Circulation, 1976, 53, 474.

(Accepted 21 December 1977)

\section{Guy's Hospital, London SE1 9RT}

DAVID PITCHER, MB, MRCP, medical registrar (now research fellow in cardiology)

DAVID MARY, MB, MRCP, honorary senior registrar (now lecturer in cardiovascular studies, Leeds)

\section{Haemarthrosis of the knee presenting as ankle bruising}

Haemarthrosis of the knee may occur after relatively minor trauma. Rupture of the knee joint is fairly common in rheumatoid arthritis ${ }^{1}$ but may also occur in degenerative disease. ${ }^{2}$ Good and Pozderac ${ }^{3}$ have recently described four patients with haemarthrosis who presented with signs and symptoms of synovial rupture and who also had extensive bruising over the lower leg extending to the ankle. Nevertheless, the degree of bruising may be much less. Kraag et al have described two patients with rheumatoid arthritis who presented with a "haemorrhagic crescent sign" at the ankles after synovial rupture. I report a patient with this sign who sustained a haemarthrosis after minor trauma.

\section{Case report}

A 64-year-old dustman presented with a five-month history of intermittent swelling of the right knee which for the previous week had been 
considcrably more swollen and painful after a minor twisting injury. He was otherwise well and no other joints were troubling him. He had a large effusion in the knee. The knee showed a good range of movement and was relatively pain free, though he had lateral instability of the joint. The calf was swollen and a little tender and there was also some pitting oedema around the ankle. There was a crescentic bruise clearly visible under the lateral malleolus (figure). Radiographs of the knee joint showed early osteoarthritic changes. Altogether $15 \mathrm{ml}$ of altered blood were aspirated from the knee joint and he was treated with rest, reaspiration, and quadriceps exercises with full resolution and return to work.

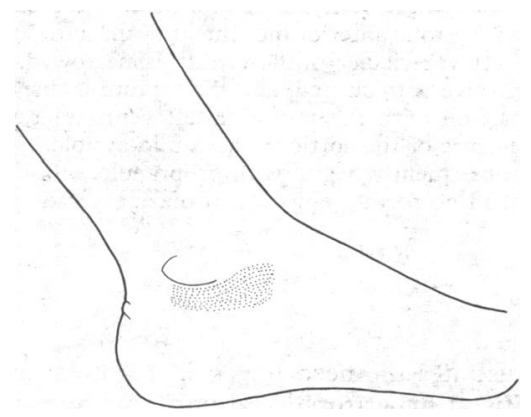

Position of crescentic bruise.

\section{Comment}

It is important to recognise the difference between deep vein thrombosis and rupture of the knee joint. The latter is benign and settles with conservative measures, while deep vein thrombosis usually requires anticoagulants-treatment that carries an appreciable morbidity. If the fluid which has leaked from a ruptured joint contains blood then ecchymosis may be present and recognition will prevent the injudicious use of anticoagulants.

${ }^{1}$ Dixon, A St J, and Grant, C, Lancet, 1964, 1, 742.

2 Bacon, P A, and Gerber, N J, Rheumatology and Rehabilitation, 1974, 13, 98.

${ }^{3}$ Good, A E, and Pozderac, R V, Arthritis and Rheumatism, 1977, 20, 1009.

${ }^{4} \mathrm{Kraag}, \mathrm{G}$, et al, Annals of Internal Medicine, 1976, 85, 477.

(Accepted 5 fanuary 1978)

Royal National Hospital for Rheumatic Diseases, Bath BA1 1RL

A K CLARKE, MRCP, consultant in rheumatology and rehabilitation

\section{Methaemalbuminaemia as a cause of cyanosis}

In the investigation of a patient with central cyanosis, an acceptable $\mathrm{PaO}_{2}$, and normal haemoglobin concentration it is a logical first step to check the blood gas results on an alternative analyser. The next step is to look for an abnormal circulating haemoglobin ${ }^{1}$; methaemoglobin may be found, ${ }^{2}$ which may be due to drug or chemical toxicity, an unstable haemoglobin $M$, or congenitally deficient methaemoglobin reductase. A blue discoloration may persist for some time after investigations, such as lymphangiography in which methylene blue or patent blue dyes have been injected. Methaemalbuminaemia is another cause, and we describe a patient in which this was present after a severe blood loss into the tissues.

\section{Case report}

A 17-year-old girl was in the front seat of a car implicated in a road traffic accident. She sustained a severe head injury, fractures of the left arm, and severe pelvic injuries with displacement of her left femur into the abdomen. The left thigh became grossly swollen and the abdomen distended and tense, with bruising around the umbilicus and on the flank. Although the external loss was estimated at under $1500 \mathrm{ml}, 15.51$ of blood, together with colloid and crystalloid solutions, were transfused during resuscitation. The resulting haemoglobin concentration was $13.5 \mathrm{~g} / \mathrm{dl}$, which fell over the next four weeks

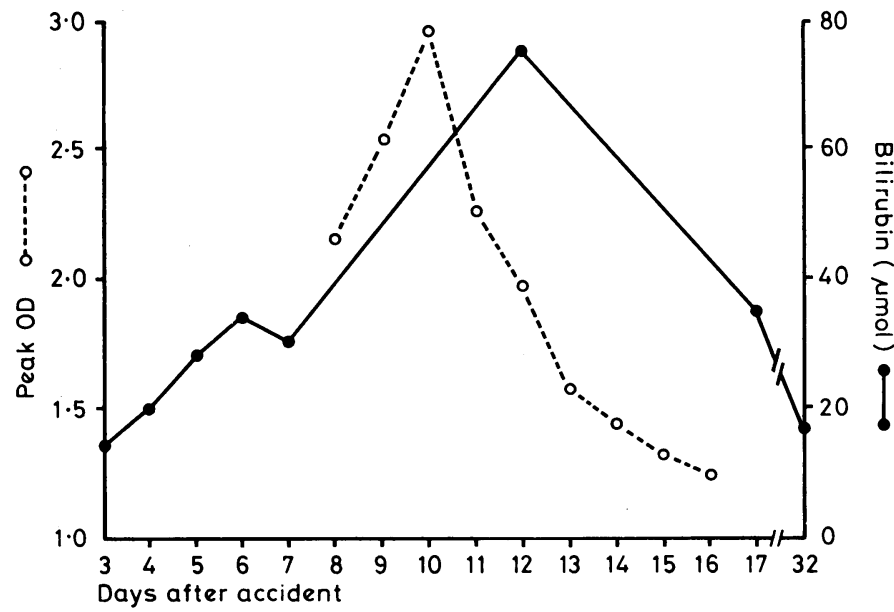

Peak ODs and bilirubin concentrations after operation.

Conversion: SI to traditional units-Bilirubin: $1 \mu \mathrm{mol} / 1 \approx 0.058 \mathrm{mg} / 100 \mathrm{ml}$.

to $12.5 \mathrm{~g} / \mathrm{dl}$. There was no evidence of intravascular coagulopathy. She was ventilated for three days and extubated after regaining consciousness on the fifth day. After extubation she was given $28^{\circ}$ " oxygen.

After 48 hours' deepening central cyanosis and increasing tachypnoea, bronchopneumonia was diagnosed and antibiotics were started. At this time the patient was afebrile, the chest $x$-ray film and ECG were normal, and there were no pathognomonic physical signs of either pneumonia or fat embolism. Blood gas analyses during this period had shown a slight fall in arterial oxygen partial pressure $\left(\mathrm{PaO}_{2}\right)$ from $10.25 \mathrm{kPa}(76.9 \mathrm{~mm} \mathrm{Hg}$ ) (saturation $\left.95^{\circ}{ }_{11}\right)$ to $9.32 \mathrm{kPa}\left(69.9 \mathrm{~mm} \mathrm{Hg}\right.$ ) (saturation $94^{\prime \prime}{ }^{\circ}$ ) in spite of increases in inspired oxygen concentration $\left(\mathrm{F}_{\mathrm{I}} \mathrm{O}_{2}\right)$ from $28^{\prime \prime}$ "to $40^{\prime \prime}$ ", but despite these measures the patient remained cyanosed. The blood gas results were confirmed using a different analyser and the blood was then screened for methaemoglobin and sulphaemoglobin with negative results. It was noted that the patient's plasma was turbid and so darkly coloured that it was difficult to see the cell/plasma interface in a haematocrit tube. The pigment was shown to be methaemalbumin. The peak optical density (OD) of methaemalbumin was measured until the cyanotic discoloration had disappeared, which occurred when the OD fell to less than 1.35 (see fig). Blood taken some six weeks later showed normal concentrations of NADH-dependent and NADPH-dependent methaemoglobin reductase.

\section{Discussion}

Methaemalbumin is formed when red cells are broken down and the capacity of the normal haemoglobin-carrying protein, haptoglobin, is saturated; the excess haemoglobin then forms a loose complex with albumin. We presume that in this patient the pigment arose from the absorption into the circulation of the breakdown products of the concealed haemorrhage. Further evidence of haemoglobin metabolism may be found by monitoring the serum bilirubin concentration (figure). Methaemalbuminaemia has been reported in association with concealed haemorrhage in acute pancreatitis, ${ }^{3}$ although it is more commonly associated with intravascular haemolysis and intramedullary ineffective erythropoiesis.

With the decrease in OD of the methaemalbumin there was a concomitant decrease in both cyanosis and tachypnoea. Since the evidence for the diagnosis of bronchopneumonia was slight, it is interesting to speculate whether the methaemalbuminaemia and the increased respiratory rate were in some way related.

We thank Dr P Emerson, Radcliffe Infirmary, for the methaemoglobin reductase estimations; Dr J H Kerr, Radcliffe Infirmary, for reading the manuscript; and $\mathrm{Mr} \mathrm{M} \mathrm{C} \mathrm{T} \mathrm{Morrison} \mathrm{for} \mathrm{permission} \mathrm{to} \mathrm{report} \mathrm{the} \mathrm{case.}$

${ }^{1}$ Schmitter, C R, jun, Anesthesiology, 1975, 43, 586.

2 Gavel, R A, and Franklin Bunn, H, Anesthesiology, 1974, 40, 516.

${ }^{3}$ Kelly, T B, et al, Annals of Surgery, 1972, 15, 175.

(Accepted 21 December 1977)

Princess Margaret Hospital, Swindon SN1 4JU

H C DRYSDALE, MRCPATH, RSC, consultant pathologis

J HUNTON, MB, FFARCS, senior registrar in anaesthetics (at present senior registrar in anaesthetics, Nuffield Department of Anaesthetics, Radcliffe Infirmary, Oxford OX2 6HE) 